\title{
Erratum to: Vapors in the ambient-A complication in tribological studies or an engineering solution of tribological problems?
}

\author{
Ala ALAZIZI, Anthony J. BARTHEL, Nicholas D. SURDYKA, Jiawei LUO, Seong H. KIM* \\ Department of Chemical Engineering and Materials Research Institute, Pennsylvania State University, University Park, PA 16802, USA \\ Received: 04 February 2015 / Revised: 14 April 2015 / Accepted: 15 May 2015
}

(C) The author(s) 2015. This article is published with open access at Springerlink.com

\section{Erratum to}

Friction 3(2): 85-114 (2015)

DOI 10.1007/s40544-015-0083-5

The original version of this article contained the incorrect caption of Fig. 7 on page 93, instead of

Fig. 7 Line profiles of the wear tracks on different glasses under different humidity conditions: (a) sodalime silicate glass; (b) fused quartz; (c) BF33; (d) AF45; (e) sodium alumino-silicate; (f) K-exchanged aluminosilicate. (a) and (b) are reproduced with permission from Ref. [110]. Copyright John Wiley and Sons, 2013. (c) and (d) are reproduced with permission from Ref. [124]. Copyright John Wiley and Sons, 2014. (e) and (f) are reproduced with permission from Ref. [125]. Copyright Springer, 2014.
It should read

Fig. 7 Line profiles of the wear tracks on different glasses under different humidity conditions: (a) fused quartz; (b) soda-lime silicate glass; (c) BF33; (d) AF45; (e) sodium alumino-silicate; (f) K-exchanged aluminosilicate. (a) and (b) are reproduced with permission from Ref. [110]. Copyright John Wiley and Sons, 2013. (c) and (d) are reproduced with permission from Ref. [124]. Copyright John Wiley and Sons, 2014. (e) and (f) are reproduced with permission from Ref. [125]. Copyright Springer, 2014. 